\title{
Mobile Learning For Preschool Education
}

\author{
G. Kokkalia ${ }^{1}$, A.S. Drigas ${ }^{1}$, and Alexandra Economou ${ }^{2}$ \\ ${ }^{1}$ NCSR DEMOKRITOS, Institute of Informatics and Telecommunications, Net Media Lab, Athens, Greece \\ ${ }^{2}$ University of Athens, Athens, Greece
}

https://doi.org/10.3991/ijim.v10i4.6021

\begin{abstract}
Nowadays preschool education is considered crucial for a child's development. Recent researches support the view that the role of kindergarten in children's progress is very important, as this age is sensitive for their future academic and social life. The use of mobile learning is recognized as a tool that can foster the knowledge and the experiences for this age and the support of specific areas according to the educational perspective. In this paper we try to give a brief overview of the most representative studies of the last decade (2005-2015), which focus on the skills that are explored in kindergarten and are supported by the mobile applications. The effectiveness of mobile learning in special preschool education is also explored.
\end{abstract}

Index Terms — preschool education, mobile learning.

\section{INTRODUCTION}

New technology is used to teach and to enhance the teaching of specific areas. Successful learning requires certain skills while metacognitive skills are fundamental to learning a range of more specific skills. They include planning, organising, monitoring and assessing one's own competencies in a variety of different areas [1]. According to existing studies, mobile devices are one of the most successful technologies for learning, as they are considered attainable and easy to use especially for people who face learning difficulties. Mobile device, which is also referred to as a handheld, is a pint-sized computing device and usually come with a touch or non-touch display screen and very often with a mini keyboard. There are different types of mobile devices, while the commonest among them are mobile phones, smart phones, PDAs, pagers and Personal Navigation Devices. PDAs and smart phones are considered the most preferred mobile devices, which offer all the advantages of a personal computer, along with a very small form factor. Additionally, their use provides greater feedback for educators and has a supportive role for learner as the provision of a necessary basis like telecommunication equipment and perfect training content are thought significant for attaining the educational goals [1].

The advent of Mobile Learning (ML) came with the invention of portable technologies and mobile devices in the 1970s and 1980s. Mobile devices have also undergone great changes and revolutions in the past few decades with the rapid development of modern science and technology. Mobile devices such as cell phones, personal digital assistants (PDAs), smart phones, etc., are carrying powerful functions, as do personal computers. Because these devices are small, smart, portable, and comfortable to utilize, particularly to the digital natives, all these devices are regarded as teaching instruments in the ML [2].
Furthermore, in recent years personal digital assistants (PDAs) have been used to replace the fragile and expensive tags, with similar learning benefits. The PDAs have the advantages that children can access further information at the moment they bump into each other, and their interactions are automatically transmitted to a large public display and added to a composite visualization of all the children's movements, representing the dynamic system being acted out in real time. Mobile learning or $\mathrm{m}$ learning (ML) has increasingly attracted the interest of educators, researchers, and companies that develop learning systems and publish instructional materials. This technology provides the potential for collaborative interaction and learning opportunities for geographically dispersed persons and groups. Although currently applied in smallscale projects, ML is potentially useful in more educational settings. Small and familiar to children mobile telephones do not require technological training, do not intimidate users, and remain a friendly tool in classrooms [3]. There are many examples of ways in which the new generation of mobile technologies is changing the way children learn. Not only is mobile learning highly engaging, it also provides children with different ways of relating their physical experiences to abstract knowledge, from running around a playground to understanding what a cell is. These innovative forms of physical digital switching are thought to lead to a more in-depth understanding of a topic. They also increase children's opportunities to make connections between their observations and ideas that can help them understand difficult concepts. Moreover, an advantage of learning while mobile is that children become more motivated and engaged than when staring at a PC while sitting still. But more significantly, mobile learning gives opportunities for ways in which children can learn. What appear to be disparate activities can now be integrated over time and space. By making more connections between their ideas, prior knowledge, and ongoing observations of the world, children are starting to view and understand the world differently. This development in educational technology represents a major topic in the way computers can be used to change children's minds. Central to these notions is the idea that mobile technologies can be designed to enable children to move in and out of overlapping physical, digital, and communicative spaces. This mobility can be achieved individually, in pairs, in small groups, or as a whole classroom together with teachers, mentors, experts, parents, professionals, and others. It is assumed that mobile technologies provide continuity across various learning experiences, enabling children to make connections between what they are observing, collecting, accessing, and thinking about over time, place, and people [4]. 
PAPER

MOBILE LEARNING For PRESCHOOL EDUCATION

Everyday observations of pre-school children's use of mobile devices are increasingly being reported in different researchers and articles while, these articles emphasize the ease with which very young children master touch-based interaction [5]. A recent review of the role of iPads for learning claiming them to have a positive impact on children engagement, increasing motivation and enthusiasm, while they improve their productivity [6]. With the increase in touch devices in homes and schools debates around the value of these technologies for play and learning have arisen. Despite of the above fact, in this paper we try to examine how the mobile applications can assess children's basic skills in kindergarten classroom. Specifically it examines the role of digital tools in literacy, math, cognitive motor and social skill development besides it investigates the role of mobile learning in children who need special education.

\section{Mobile ApplicAtions That Assess Literature} SKILLS

In kindergarten education, there have been conducted several studies that claim that properly designed digital educational activities can become an important educational tool for efficient and effective learning especially in the field of the early literacy skills. A wide variety of mobile multimedia applications have become increasingly accepted as developmentally appropriate education resources for children's spoken and written language development. Research has shown that children who do not already have a good start in literacy development by the time they reach school rarely learn to read on schedule and continue to have difficulty throughout elementary school. Thus, early intervention during the preschool years is critical not only for children who are at risk of facing learning difficulties [7].

In addition, supporters have seen the integration of handheld computers as a way to enhance student learning and achievement. Evidence of kindergarten classes' handhelds use in such curriculum areas as reading, mathematics, social studies and science prove promising practices in this domain [8]. As PDA's, cell phones and mp3 players have converged and altered into more sophisticated mobile devices, the iPod Touch has emerged as a pocket computer with multiple kindergarten classroom possibilities. The iPod Touch (and the iPhone) is equipped to perform a multitude of complex tasks, many of which can be ordained to fill many of educational objectives especially in the domain of the early literacy skills. These devices are inexpensive, compared to classroom laptop carts or computer labs, and their portability and durability provide students with potential learning tools that meet the classroom and the home [9]

Taking the above into consideration, the purpose of a recent study was to develop a mobile phone based intervention that would encourage parents to engage their children in daily literacy-learning activities. The intervention included text messages for parents, audio messages for parents and children, and Sesame Street letter videos for children [10]. According to the developers, this study reports the design and implementation of an intervention using Sesame Street content intended to encourage parents to engage their preschool children in literacy learning. The intervention reported here was designed to deliver Sesame Street educational materials focused on learning letters via mobile phone to parents and preschool children from lower and middle-income families. This intervention applied the elements of Fogg's "functional triad" model [10] of persuasive technologies in the context of using mobile phones to encourage and persuade parents to engage their young children in activities that are known to lead to growth in literacy skills. In addition, the findings of the study indicate that this mobile technology-based literacy intervention seemed as a highly effective use of persuasive technology. Participants reported that the use of mobile phones is considered very helpful for them as they had access to it while they were at home, in the car, in playground or in another location. Moreover, parents in this study stated that the ready access provided by mobile delivery made it extremely easy for them to fit literacy activities into their normal daily routines with their children. Finally, the technology-based persuasive messages inspired participants to engage in behaviours that would lead to increased literacy skills in their children [11].

Furthermore, the increased acquisition of touch-screen technologies, such as tablet computers, in both homes and schools raises important questions about their role for very young children's learning and development. Their inherent touch-based interaction offers new opportunities for mark making practices, which are linked to literacy development, through the emergent process of using marks as symbolic representation [12]. A recent research reports a comparative study of touch-based interaction using a tablet computer versus traditional physical paint and paper. Children aged 2-3 years engaged in a free finger painting activity and colouring in activity in both paper and digital environments. Video data of their interactions was used to develop a coding scheme for analyzing touch-based interaction, providing insight into how the use of fingers and hands differed in each environment, the different types and qualities of touch that were engendered, and the composition of the final paintings produced. Findings show that while the tablet computer limited the number of fingers used for interaction, its material affordances supported speed and continuity, which led to more mark making, and different 'scales' of mark making extending the range of mark making practices. At the same time it limited the sensory experience of physical paint and resulted in more uniform final compositions. The findings indicate differential benefits and limitations of the use of iPad's (or touch screen technologies) in pre-school learning contexts, and overall seem to suggest that these technologies should be used as a complement to other activities, without lessening a prioritizing of messy, sensory experiences, such as physical painting, at this stage of child development. While the iPad environment did not engender new forms of touch movements in this age group (in the context of emulating a non-digital practice), it did engender more mark making overall with longer sequences of continuous interactions and complex linking of different touch types. These attributes suggest that the iPad facilitates important mark making activity in pre-school children, extending the kind of mark making possible with traditional physical materials, and offering a medium through which children can potentially develop important pre-requisite skills for writing and drawing. In addition, the results show how early engagement with touch screen technologies may be valuable in fostering the development of digital literacy skills, such as swiping. However, the iPad was found to restrict the use of multiple digits and hands in touch based contexts, encouraging far more index finger interaction, as 
well as precluding sensory tactile experiences enabled through paint and paper based interaction [13].

Additionally, Alphabet book is an important instructional tool that is used in early education. Advances in mobile technology have led to alphabet books of an electronic format with accompanying sound, animations, and interactive hot spots in order to expose children to reading and writing. A recent experimental training study investigated the effectiveness of paper alphabet books and alphabet eBooks in training alphabetic knowledge in 4-yearolds [14]. Three groups of approximately 30 children were assigned to one of three conditions: paper alphabet book, alphabet eBook, or storybook control. Book reading sessions composed of three to four children were run twice a week over eight weeks, with child-book behaviours coded at each session. The purpose of this study was to examine the effect of providing children with alphabet eBooks loaded onto an iPad tablet on their emergent literacy development. Emergent literacy was assessed according to children's letter-name and letter-sound knowledge, and phonological awareness prior to and following treatment. The alphabet eBooks represented a sample of commercially available alphabet eBooks that include interactive features while the paper alphabet books represented a range of alphabet books on the market with detailed colourful illustrations and accompanying text. It was hypothesized that children in the eBook condition would show the greatest improvement from pre-test to post-test in lettername, letter-sound, and phonological awareness scores, followed by the paper alphabet condition, with the control group showing the lowest improvement. However, the results of the study showed that alphabet eBooks seemed to be no more effective than their paper counterparts nor than storybooks at encouraging early literacy knowledge have important implications for educators and those who develop electronic children's books. Furthermore, the present study showed that alphabet eBooks, with their addition of letter and object hotspots, succeeded in engaging children's attention. Also, that increased engagement or orientation to the books did not translate into increased literacy knowledge and the researchers support that this is not to say that all alphabet eBooks are problematic or ineffective, but the present study results cast doubt on the claims made by promoters [14].

\section{Mobile ApPlicAtions That AsSESS EARLy} MATH SKILLS

According to research in the area of mathematical education, using technology is an integral part of fostering mathematics from an early age in the kindergarten (National Council of Teachers of Mathematics [NCTM], 1989) [15]. At this age children develop many mathematical concepts, at least in their intuitive beginnings, even before they reach school age. It is well known that infants occasionally recognize and discriminate among small numbers of objects, and many preschool children possess a substantial body of informal mathematical knowledge. Besides, it is widely accepted that being engaged in multimedia embedded with mathematics from the youngest age can provide opportunities for thinking and exploring [16]. However, it is already known that early years are the important years to develop children concepts and also critical and creative scientific thought [16]. A kindergarten child also needs the opportunity to apply its skills in a variety of learning environments, and is strongly recom- mended that the digital learning media can contribute to the learning of mathematical skills. Many aspects of early informal learning of mathematical concepts, such as numbers, arithmetic problem solving, and spatial syllogism along with general geometrical knowledge, are developed during the kindergarten age.

In recent years, with the appearance of smart applications and programs several researchers have proposed the use of many devices such as tablets and mobiles [17]. Particularly in the subject of mathematics, Zaranis [17] made a comparison between the learning outcomes of computer based teaching and mathematical thematic teaching, aiming the teaching of "Realistic Mathematics" for kindergarten children. Compared to the traditional teaching method, results showed that mobile learning enhance the development of mathematical skills and the cultivation of a deeper perceptual ability for the pupils.

Additionally, in the area of mathematics education it is believed that Web Apps for the iPod Touch provide many ways for students to practice and explore mathematical problems. Firstly, Flash Math is a basic drill program that presents the child with a set of timed problems. Settings for addition, subtraction, multiplication, and division, as well as choices for the number of place values to include in problems the number of problems to present, the time for each problem and progressive time adjustments makes this application friendly for the student. As a result, teachers could certainly use this application to provide individual students with the types of arithmetic practice that they need in order to become more proficient in their mathematics classroom. In addition, Math Quiz expands this type of work to include squares and square roots and includes controls for presenting problems in random or sequential order. The problems are answer via a type spin wheel with audio clicks, which could be entertaining for the students using the app. Math Quiz continues to provide problems to the user for the duration of the experience nevertheless the lack of a stopping point could be a frustration for some students, but others could find that they enjoy the continual challenge [18].

In addition, Tomi and Rambli [19] in their research present the development of an interactive mobile augmented reality magical playbook for preschool children in learning numbers using an old folklore literature, The Thirsty Crow, via mobile augmented reality application and interactive physical book interface design. According to the authors, Augmented Reality (AR) refers to a technology that gives the ability to the user the sense of the real world while interacting with the virtual and physical object. Additionally, mobile AR application has gaining popularity nowadays due to mobile technology advancement. Mobile refers to portability usefulness of the application itself, thus mobile AR application can be referred as a portable AR application. By applying this concept to AR storybook, the physical book will be enhanced by augmenting the virtual object (3D models, animations, and sounds) viewed over a mobile device. This study specifically highlights an innovative development of the interfaces for providing an AR storybook that enhances story reading and learning experience for preschool children via mobile AR application and highly interactive physical book interface design of the AR book. The findings of the study suggest that AR concept of the book successfully grabs children's attention while this application with the 
book is easy to use especially for young children. Furthermore, the children would likely to interact with the 3D character on the book besides their excitement of interacting with the book's character using their finger on their reaction. Finally, in math section, students were excited to count together with the 3D character while interacting with the book. Thus, it shows the users were fully engaged with learning process in a joyful learning environment [19].

\section{Mobile Applications That Assess Cognitive SKILLS}

Knowledge can become meaningful and purposeful if it is related to children's daily life and experiences. Through new technology based tasks children cope with a simulation of the real-world, make use of cognitive mechanisms and gradually construct knowledge because technology provides situational and visual cues that allow children to think, work out, interact, collaborate, create and finally learn [20]. Nowadays, touch screen devices allow for a much easier interaction for preschoolers than any other technology. According to a very recent study, which was carried out in 2012, media tablets experienced the highest increase in usage among children ages 4-14 years old with usage highest among younger children [21].

Researchers have examined children's cognitive skill development with digital media and have found that welldesigned mobile -based learning activities and games can improve skills of abstract thinking, reflective thinking, and analyzing and evaluating information planning and scientific reasoning. Eye-hand coordination has improved with the use of computers at home and at school [22]. Also, young children have improved in problem-solving skills, spatial cognition, spatial representation, iconic skills, and visual attention skills when using computers, mobile and video games in school and for entertainment during leisure time at home. As a result, the use of digital media has been compared to traditional methods for teaching cognitive skills, and the research has found that digital media were more effective in specific cases. Besides, there is a general belief that kindergarten children developed stronger increases in memory when they used computers for learning compared to learning without new technology and multimedia [23]. More recently, a genetics simulation was developed using the Thinking Tags in order to help very young children to learn about dental hygiene. According to many dentists, children find it difficult to understand how eating candy and drinking sugary drinks can cause their teeth to rot. Tooth decay caused by the buildup of sugar is a difficult concept for young children to learn. Instead of being taught about dental health with the traditional way, five-year-old children used Thinking Tags to experience improving or decaying dental health [24]. In this context, the digital tags were used to simulate the decay process, enabling the children to experience it firsthand and then talk about it. The technology provided a much more accessible way of learning about a difficult topic.

A similar study proposed a Playful Toothbrush system using UbiComp technology to provide play-based occupational therapy for improving tooth-brushing skills in kindergarten children. The design of the Playful Toothbrush digitally interfaces physical tooth brushing activity with a computer game to guide children in learning proper brushing techniques and to reinforce active participation of children in brushing activity. The user study results suggest that the Playful Toothbrush improves the tooth brushing skills of kindergarten children within a relatively short training period. After using the Playful Toothbrush for five days, kindergarten children exhibited significant improvement in effectiveness of teeth cleaning, increased number of brushing strokes, longer brushing time and more thorough brushing coverage in teeth areas. According to the designers, the contribution of the UbiComp is that it has potentials for making many repetitive and complex developmental tasks attractive and simple to a young child [24].

Furthermore, the iPod Touch and the iPhone are equipped to perform complex tasks, many of which can be used for different educational objectives. The iPod Touch evolved from Apple's earliest MP3 player and equips the iPod Touch with many media capabilities. The handheld computer manages and plays/displays audio, image, and video files. While some researchers may find the premise of young children benefitting from the use of mobile devices to be far-fetched, preschoolers are demonstrating that they can understand and interact with Web applications such as Preschool Adventures, At the Zoo, and Wheels on the Bus, ABC Letters, and iDoodle. These applications are well aligned with the spirit of early childhood education and technology use, as articulated by the National Association for the Education of Young Children. Children are encouraged to play and discover, as they engage with these applications. Pre-School Adventures provides an interface for exploring concepts of colors, shapes, sounds, and body parts. Users select a topic represented with visual and auditory cues, and continue to receive feedback in this way as hey make selections. At the Zoo provides children with images of about 20 animals that they will encounter in many zoos. Using these fingertip-sized images, users may choose to hear the sounds that each animal makes, or hear and see the spellings of the animal names. ABC Letters quizzes little ones with blocks of letters aurally asks them to select a particular letter, and provides feedback after the response while users can elect to hear the letter name again, even when they provide a correct answer, showing the letter name with the visual image of the letter. Digital audio books, such as The Little Pine Tree, present images and text, one page at a time, with audio, allowing young learners to hear and see the story, and flip through the pages with a flick of a finger. Shadows Never Sleep is a "zoom narrative" which entices readers to explore the story by using the multi-touch zoom feature to discover the story line. Applications like iDoodle 2 provide a way for children to draw with their fingertips, selecting a variety of colors, lines, fills, and thicknesses. Double-clicking to zoom in and out of these sketches provides young ones with choices of how to view their creations. Each of these Web applications could potentially be integrated into the curricular content of the early childhood classroom, providing teachers and students with resources to support learning and achievement [25].

\section{Mobile Applications That Assess Social- EMOTIONAL SKILLS}

Collaborative learning and social interaction skills can be enhanced with well-designed digital technology Existing studies note that young children who share the new technology, work in an equitable and cooperative manner 
PAPER

MOBILE LEARNING For PRESCHOOL EDUCATION

showing a preference for working with peers cooperatively [26]. Moreover, according to O'Hara when young children use new technology are encouraged to discuss the stories, share their ideas and move characters around using the touch sensitive screen accompanied by much advice from their peers. The findings of the specific research claim that when settings include multimedia into imaginative and role-play areas, the fact of social behaviour and communication is notably high when also teacher's guidance is present. Research has also shown increases in young children's motivation to learn when they are involved with engaging and fun digital media. Mobile learning activities can elicit high levels of interest in and focus on the learning task that does not tend to diminish over time and young children reported high levels of enjoyment and engagement [27].

Furthermore, mobile learning tends to facilitate the procedure of new information and increase deduction. When a student learns, the new content when presented in both visually and non-visually, meaningful learning occurs concluding that meaningful learning facilitates the storage and recall of new information. An existing study examined the implementation of an e-book shared reading in preschool classrooms. Observations focused on teachers' implementation of a vocabulary focused shared book routine, language strategies at the touch screen, mobile devices to extend the shared reading experience, and children's learning and entertainment. Participants included a diverse sample of 28 children that browsed or reread stories on a mobile device (iPad or iPod). Results suggest a relatively easy transition from traditional to e-book shared reading that may support children's word learning, but may not maximize the potential of e-books for instruction and independent reading. Moreover, the results point to the promise of e-books for supporting word learning in the preschool classroom as children seemed to enjoy and like to participate in this. As the authors believe, the e- book may extend the opportunities for word learning in the early literacy curriculum. Along with traditional shared book reading and read aloud activities, teachers can use ebooks to further expose children to vocabulary words and make the learning environment more pleasant [28].

Also, Horowitz et al. [29] examined the efficacy of video streaming lessons via cell phones as a means of increasing letter knowledge and motivation of preschool students. Participant families streamed two types of video clips to their cell phones: literacy tips for parents on integrating letter knowledge into daily activities, and Elmo "Letter of the Day'clips. Participant families were required to stream three sets of these videos, each set comprised of one literacy tip and one "Letter of the Day", weekly for a period of eight weeks. Participant report and observation indicated that the combination of literacy teaching tips and instructional alphabet clips showed great potential as a means of supplementing literacy instruction. In addition to resulting in increased alphabet knowledge of participants, the video streaming was reported to ease access to educational information for parents, provide a venue for easy everyday integration of literacy learning, and encourage enthusiasm and motivation.

Another tool, Savannah was designed as a game to be played outdoors to develop children's understanding of animal behavior through their interactions on a virtual plain. Global positioning system (GPS) enabled handheld computers presented a virtual savannah that digitally over- laid a school playing field and was populated by animals that would normally be found there. Each child took on the role of a lioness and had to hunt other animals, such as antelopes, to survive. This involved the children working in teams, as though they were hunting as a pack. As they moved around the playing field, the children's mobiles kept track of where they were and popped up pictures of their surroundings, including animals that were close by. The children's energy levels were also shown using simple graphical representations, indicating when they needed to eat to stay alive. Remote facilitators occasionally sent messages to them via the mobiles to keep them in the game. The children then returned to the classroom to talk about their experiences and learn more about the animals' behavior. An evaluation of the game suggested that it encouraged self-directed learning. However, the children sometimes found it difficult to match up the images of animals they saw on their PDAs with the empty playing field while a considerable amount of imagination was required to play the game [30].

\section{Mobile Applications That Assess Motor SKILLS}

Mobile technologies have been incorporated into a number of physical activities to encourage children's understanding of abstract phenomena. With computers and other similar devices occupying an increasingly important place in early years education, it is perhaps not surprising to find concerns being raised about their impact on the young child's physical development, as well as health and safety issues. According to several studies, varying degrees of proficiency in individual manipulation of the mouse and keyboard are observed. On the other hand, in early childhood settings, mobile technology research has emphasized foundational motor skill development. Some children seem to be experienced at moving the cursor about the screen and mouse clicking on various objects, whereas others experience considerable difficulty in performing tasks that ask demands on their hand- eye coordination. It is agreed that becoming familiar with using the mouse and keyboard requires a good deal of practice, but observations from a relevant study would suggest that the young child's ability in letter recognition also has an important role to play in developing keyboard skills. Moreover, it is accepted by the teachers that computer and other devices use appear to enhance development of the young children's hand-eye coordination and fine motor skills [31].

Taking the above into consideration, FloorMath combines a sensor-embedded floor mat with a visual representation of the number system that appears on an adjacent screen. When children walk up and down the squares, the corresponding numbers change on the screen. Walking the numbers is thought to make the activity more meaningful, helping children to see and understand abstract concepts in a new way [32]. Similarly, SmartStep, developed by the same researchers, requires children to play hopscotch, skip, and count at the same time when practicing basic math skills. This combination of physical and mental activities is meant to hone motor skills, pattern recognition, rhythm, and coordination.

Furthermore, another study assessed the effectiveness of two research-based, educational literacy applications the Dog Party and the Super Why. Researchers gave 90 children (ages 3-7) an iPod touch on which to play the two 
applications over two weeks. Their parents completed observation logs, and the children were given a pre- and post-test to assess their ability in motoring skills and content areas covered in the applications. The results of the studies showed that children learn successfully when use such devices while children exercise their motor abilities and the eye-hand coordination [33].

Additionally, another work analyzed about 100 commercial applications running on multi-touch devices for pre-school children and noticed that $99 \%$ of the applications used tap and $56 \%$ used drag gestures as their only supported operations. In order to analyze children's capacity to successfully perform additional gestures the researchers conducted an experimental evaluation in which pre-school children participated as users of a multi-touch application requiring different types of operations, such as tap, drag, scale up, down, and one and two finger rotation. The findings of the study suggest that additional gestures may be effectively incorporated into applications targeting pre- kindergarten users and running on multi-touch devices with little implementation effort. The analysis of these limitations gave a set of design guidelines that address boundary exit conditions and coordinated interactions [34].

Also, Nintendo Wii applications are also beginning to be used for learning various physical and cognitive skills. Vannoni and Straulino [35] showed that children were able to learn about force, velocity, and acceleration through using a Wii remote to measure acceleration of a swinging pendulum. All these applications use mobile technologies to bootstrap physical activities with learning math, physics, or other cognitive skills. At the same time, if the physical exercise is designed to be strenuous, children's health can equally benefit through the children having to run, walk, or cycle while learning.

Last but not least, Yu et al. [36] assessed the design of the interaction aspect of touch screens in order to develop digital educational games. They tested the effectiveness of 5-6 year-olds in four game prototypes while dragging, clicking, rotating and zooming. Their findings showed that pre- school children were not familiar with rotating and zooming and that they needed at least six minutes of training time. They also found that the main cause of the problem was the gap between the sensitivity of the device and the precision of the action required for the game. One of their negative findings was that more than half of the children rested their non-operational hand on the screen while using the interface.

\section{Mobile ApPliCATIONS ThAT AsSEss CHILDREN WiTH SPECIAL NEEDS}

Many researchers support the view that children with special education needs face difficulties to develop cognitive abilities and acquire new knowledge. According to many studies, these children have to improve their behaviour, communication and relationships with their environment in order to improve their learning and daily life. The development of appropriate and adaptable applications provides them with many benefits as it helps to improve the learning process to different cognitive, sensorial or mobility domain [37].

Taking the above into account, Fernadez- Lopez et al. [38] developed a platform called Picca, for children with educational special needs . The designers made a mobile platform, based on iPad and iPod touch devices, in order to cover the 3 main phases of the learning process: preparation, use and evaluation. This platform includes four kinds of educational activities, which can be used by educators depending on children requirements. The results of their experiment shows that the use of the Picca is associated with positive effects in the development of learning skills for children who have special educational needs, claiming that the basic skills have been improved. Besides, in many cases children have the opportunity to perform activities that previously were not accessible to them, because of the interface and contents of the activities have been adapted specifically to them. The study also suggests that the type of activities provided is developmentally appropriate for learning purposes as well as the use of electronic devices and multimedia contents increases children's interest in learning and attention.

Moreover, another study compared the advantages of mobile phones as a management device for caring with lecture that is thought the main method for parent's education in this topic. In this survey 60 mothers who have a child with ADHD were selected and divided in two groups. After the pre-test that was based on knowledge and practice about ADHD and its management, one of the groups received educational support from mobile phone and for the other group, lecture was held on. After 16 weeks, the investigators re- measured knowledge and level of applying of the trained techniques. The findings of the survey state that although both training methods had a positive effect on knowledge and management techniques for mothers, the use of mobile phone as a learning supportive and assessment tool, seem to be more effective. Specifically, the mothers who joined the mobile learning group were successful to control the ADHD symptoms in their children than the mothers in lecture group [39].

Other meaningful approaches, focused on the use of touch-screens by children with some type of cognitive disorder. Their study showed that it is possible to obtain significant results, especially in promoting collaboration and motivation, although these studies cannot be taken as a reference for normal children's behaviour with touchscreens. Furthermore, many studies support the view that iPad applications are being used as a tool for learning within educational environments. A recent pilot study investigated the efficacy of iPad applications in improving the literacy and general academic skills in at-risk preschoolers. The findings of the study indicated that practical significance was found for the use of iPad applications to support learning in the preschool skill areas of alphabet knowledge and number concept [40].

Although most information about touch device use by people with disabilities may be in the popular media there is research on the use of touch devices with people with developmental disabilities. Recent reviews have covered the use of iPods and iPads in teaching programs for people with developmental disabilities and more specifically, with autistic spectrum disorders [41]. This systematic review aimed to evaluate the use of iPods, iPads and related devices in educational programs for individuals with developmental disabilities. A systematic search identified 15 studies in which the results were largely positive, suggesting that such devices are important technological aids for individuals with developmental disabilities. The results of these studies also claim that children with developmental disabilities can be taught to use such devices for a 
variety of purposes, specifically for enhancement of academic, communication, and other basic skills. On the other hand, the authors state that some individuals showed difficulty in learning to operate such devices with sufficient motor control, suggesting that other solutions such as Bluetooth can be arranged [41].

\section{CONCLUSIONS}

With the increasing use of interactive mobile technology, mobile applications have become a powerful tool of living and learning in preschool education. As defined by the Global System for Mobile Communications in their report, Handheld mobile technologies are emerging in classrooms, as they seem to support children with special need while they increase motivation to learn, improve fluency skills, encourage collaboration, and improve reading comprehension. As a result, research in mobile technology is considered as a supplemental teaching tool for children and shows promising findings. However, according to this short review is thought significant the research in the area of the special education in preschool education. The sensitive and important age of the preschool children asks for more investigation and especially in the area of the learning difficulties and their assessment with the support of the mobile applications. Despite the fact that the increasing interest in this age is considerable, besides there is place for more studies and development of mobile applications, which can assess and help children, which face learning and developmental difficulties.

\section{REFERENCES}

[1] Chiong, C., \& Shuler, C.: Learning: Is there an app for that? Investigations of young children's usage and learning with mobile devices and apps. New York: The Joan Ganz Cooney Center at Sesame Workshop 2010

[2] Edwards, A., Elwyn, G., \& Mulley, A.: Explaining risks: turning numerical data into meaningful pictures. BMJ: British Medical Journal, 324, pp. 827-834(2002) http://dx.doi.org/10.1136/bmj. 324.7341.827

[3] Cavus, N., \& Uzunboylu, H.: Improving critical thinking skills in mobile learning. Procedia-Social and Behavioral Sciences, 1pp. 434-438(2009)

[4] Chiong, C., \& Shuler, C.: Learning: Is there an app for that. In Investigations of young children's usage and learning with mobile devices and apps. New York: The Joan Ganz Cooney Center at Sesame Workshop (2010)

[5] Clark, W., \& Luckin, R.: iPads in the Classroom. What The Research Says (2013)

[6] Plowman, L., Stephen, C., McPace, J.: Supporting young children's learning with technology at home and in preschool. Research paper in Education 25, pp/93-113 (2010)

[7] Shoemaker, L. P.: Handhelds for reading and note taking. Learning and Leading with Technology, 35, pp.36-49, (2007)

[8] Auchincloss, C., \& McIntyre, T. : iPod "Teach": Increased access to technological learning supports through the use of the iPod Touch. Journal of Special Education Technology, 23, pp.45-49, (2008)

[9] Swan, K: Highly mobile devices, pedagogical possibilities, and how teaching needs to be conceptualized to realize them. Educational Technology, 47, pp.10-12, (2007)

[10] Fogg, B.J.: Persuasive Technology: Using Computers to Change What We Think and Do. Morgan Kauffman Publishers, San Francisco, CA. 2003

[11] Druin, A.: Mobile technology for children: Designing for interaction and learning. Morgan Kaufmann (2009)

[12] Price, S., \& Rogers, Y.: Let's get physical: the learning benefits of interacting in digitally augmented physical spaces. Computers and Education, 43pp. 137-151(2004)
[13] Ihmeideh, F. M.: The effect of electronic books on enhancing emergent literacy skills of pre-school children. Computers \& Education, 79, pp. 40-48(2014) http://dx.doi.org/10.1016/j.compedu. 2014.07.008

[14] Willoughby, D., Evans, M. A., \& Nowak, S.: Do ABC eBooks boost engagement and learning in preschoolers? An experimental study comparing eBooks with paper ABC and storybook controls. Computers \& Education, 82, pp. 107-117(2015) http://dx.doi.org/10.1016/j.compedu.2014.11.008

[15] Institute of Education Sciences, National Center for Education Statistics, US Department of Education: National Assessment of Educational Progress (NAEP) (2005)

[16] Zaranis, N., Kalogiannakis, M., Papadakis, S: Using Mobile Devices for Teaching Realistic Mathematics in Kindergarten Education. Creative Education 4,pp. 1-10 (2013) http://dx.doi.org/10.4236/ce.2013.47A1001

[17] Zaranis, N. : The influence of ICT on the numeracy achievement of Greek kindergarten children. In Moreira, M., Loureiro, J., Balula, A., Nogueira, F., Pombo, L., Pedro, L., \& Almeida, P. (Eds.) Proceedings of the 61st International Council for Educational Media and the XIII International Symposium on Computers in Education (ICEM\&SIIE’2011) Joint Conference p.p.390-399, University of Aveiro, Portugal (2011).

[18] French,D.P .:iPods:Informative or invasive?Journal of College ScienceTeaching, 6, pp.51-59 (2007)

[19] Tomi,A \&Rambli,D.: An Interactive Mobile Augmented Reality Magical Playbook: Learning Number With The Thirsty Crow. Procedia Computer Science 25, pp. 123-134, (2013) http://dx.doi.org/10.1016/j.procs.2013.11.015

[20] Stephen, C., Plowman, L.: A 'benign addition'?Research on ICT and pre-school children. Journal of Computer Assisted Learning 19 , pp. 149-164, (2003) http://dx.doi.org/10.1046/j.02664909.2003.00016.x

[21] Robledo-Rella, V., Aguilar, S. Shea, R. Pérez-Novelo1, E. Ortega1, J.C. Olmedo, J. Noguez, E. Tamés,J., and Toiminen, R.: Design and evaluation of mobile learning resources in mathematics for public elementary schools in Mexico. IADIS International Conference Mobile Learning 2012

[22] McTavish, M: "I get my facts from the internet": A case study of the teaching and learning of information literacy in in-school and out-of-school contexts "e Journal of early childhood literacy 9, pp. 3-28 (2009) http://dx.doi.org/10.1177/1468798408101104

[23] Burnett, C.: Technology and literacy in early childhood educational settings: a review of research. Journal of early childhood literacy, $\quad 10, \quad$ pp. $247-270,2010 \quad$ http://dx.doi.org/10.1177/1468 798410372154

[24] Chang, Y. C., Lo, J. L., Huang, C. J., Hsu, N. Y., Chu, H. H., Wang, H. Y., \& Hsieh, Y. L.: Playful toothbrush: ubicomp technology for teaching tooth brushing to kindergarten children. In Proceedings of the SIGCHI Conference on Human Factors in Computing Systems (pp. 363-372). ACM (2008, April) http://dx.doi.org/10.1145/1357054.1357115

[25] Savilla Banister: Integrating the iPod Touch in K-12 Education: Visions and Vices, Computers in the Schools: Interdisciplinary Journal of Practice, Theory, and Applied Research, 27, pp. 121131, (2010) http://dx.doi.org/10.1080/07380561003801590

[26] Bers, M., Rogers, C., Beals, L., Portsmore, M., Staszowski, K., Cejka, E.,\& Barnett, M.: Innovative session: early childhood robotics for learning. In Proceedings of the 7 th international conference on Learning sciences pp. 1036-1042, International Society of the Learning Sciences (2006)

[27] O'Hara, M.: Young children, learning and ICT: a case study in the UK maintained sector. Technology, Pedagogy and Education 17, pp.29-40 (2008) http://dx.doi.org/10.1080/14759390701847443

[28] Papastergiou, M.: Digital game-based learning in high school computer science education: Impact on educational effectiveness and student motivation. Computers \& Education, 52,pp. 112(2009) http://dx.doi.org/10.1016/j.compedu.2008.06.004

[29] Horowitz, J., Sosenko, L., Hoffman, J., Ziobrowski, J., Tafoya, A., Haagenson, A., Hahn, S.: Evaluation of the PBS Ready to Learn Cell Phone Study: Learning Letters with Elmo. Final Report to the U. S. Department of Education (September 2006)

[30] Facer, K., Joiner, R., Stanton, D., Reid, J., Hull, R., \& Kirk, D.: Savannah: mobile gaming and learning? Journal of Computer As- 
sisted Learning, 20, pp. 399-409(2004) http://dx.doi.org/10.1111/ j.1365-2729.2004.00105.x

[31] Haugland, S.: What role should technology play in young children's learning? Young Children, 55, pp.12-18 (2000)

[32] Scarlatos, L., Lowes, S., Sklar, E., Chopra, S., Parsons, S., Rudowsky, I., \& Holder, H.: Building bridges: the 2006 summer institute. Journal of Computing Sciences in Colleges, 23, pp. 2330(2008)

[33] Martin, E., Morgan, M. C., \& Rukobo, E.: Play-Based Technology Platforms and Early Learners (2014)

[34] Nacher, V., Jaen, J., Navarro, E., Catala, A., \& González, P.: Multi-touch gestures for pre-kindergarten children. International Journal of Human-Computer Studies, 73, pp. 37-51(2015) http://dx.doi.org/10.1016/j.ijhcs.2014.08.004

[35] Vannoni, M., \& Straulino, S.: Low-cost accelerometers for physics experiments. European Journal of Physics, 28, pp. 781-790(2007) http://dx.doi.org/10.1088/0143-0807/28/5/001

[36] Yu, X., Zhang, M., Ren, J., Zhao, H., Zhu, Z.: Experimental development of competitive digital educational games on multitouch screen for young children. In: Proceedings of the 5th International Conference on E-learning and Games, Springer, pp. 367375 (2010) http://dx.doi.org/10.1007/978-3-642-14533-9 38

[37] Brown M\& Harmon M.:iPad Intervention with At-Risk Preschoolers: Mobile Technology in the Classroom Journal of Literacy and Technology 56, pp. 1535-0975 (2013)

[38] Fernández-López,A., Rodríguez-Fórtiz,M., RodríguezAlmendros,M., Martínez-Segura,M.: Mobile learning technology based on iOS devices to support students with special education needs. Computers \& Education 61, pp. 77-90 (2013) http://dx.doi.org/10.1016/j.compedu.2012.09.014

[39] Kharazmi, R. Najafi, M., Khoshnavay,F. : Mobile phone an effective tool for management process of ADHD. International Journal of Managment, IT and Engineering, 3, pp. 141-151(2013)

[40] Stephenson, J., \& Limbrick, L: A review of the use of touchscreen mobile devices by people with developmental disabilities. Journal of autism and developmental disorders, pp. 1-15(2013)

[41] Kagohara,D., van der Meer,L., Ramdos,S.,O’Reilly ,M., Lancioni,G., Davis,T., Rispoli ,M.,Lang,R., Marschik,P., Sutherland,D., Green,V., Sigafoos. J.: Using iPods1 and iPads1 in teaching programs for individuals with developmental disabilities: A systematic review. Research in Developmental Disabilities 34, pp. 147-156 (2013) http://dx.doi.org/10.1016/j.ridd.2012.07.027

\section{AUTHORS}

Athanasios Drigas is a Research Director at IIT, N.C.S.R. Demokritos. He is the Coordinator of Telecoms $\mathrm{Lab}$ and founder of Net Media Lab since 1996. From 1990 to 1999 he was the Operational manager of the Greek Academic network. He has been the Coordinator of Several International Projects, in the fields of ICTs, and eservices (e-learning, e-psychology, e-government, einclusion, e-culture etc). He has published more than 270 articles, 7 books, 25 educational CD-ROMs and several patents. He has been a member of several International committees for the design and coordination of Network and ICT activities and of international conferences and journals. Also he has accepted several distinctions for his work (articles, projects, patents) (e-mail: dr@iit.demokritos.gr).

Alexandra Economou is an assistant professor at the University of Athens in the department of Psychology. She teaches undergraduate and postgraduate neuropsychology and experimental psychology courses at the University of Athens in the Department of Psychology while her interests focus on cognitive and biological psychology. Dr. Economou is also vice-president of the Greek Aphasia Association. (E-mail: aoikono@psych.uoa.gr)

Georgia Kokkalia (MSc in Specific Learning Difficulties) is a Special Education Teaching Professional. She has participated in various research projects regarding the use of Information and Communication Technologies (ICTs) in Special Education and in Kindergarten. (e-mail: gioulina@hotmail.com).

Submitted 07 July 2016. Published as resubmitted by the authors 23 September 2016. 